\title{
INTERPRETIVE SUMMARIES, JUNE 2013
}

Invited review: Reduced milking frequency: Milk production and management implications. By Stelwagen et al., page 3401. Reducing milking frequency in dairy cows to once daily reduces milk yield; however, it also offers a viable management tool, particularly in less intensive dairy systems based around grazed pasture. In addition to reducing labor requirements and farm working expenses, once-daily milking improves energy balance and decreases body condition loss in cows during early lactation. There may also be associated benefits of once-daily milking on reproductive performance and animal health, without compromising the welfare of the cows.

http://dx.doi.org/10.3168/jds.2012-6074.

A mild pulsed electric field condition that improves acid tolerance, growth, and protease activity of Lactobacillus acidophilus LA-K and Lactobacillus delbrueckii subspecies bulgaricus LB-12. By Najim and Aryana, page 3424. Lactobacillus acidophilus and Lactobacillus delbrueckii ssp. bulgaricus are known probiotic bacteria. This study identifies mild pulsed electric field conditions that enhance some beneficial characteristics of these bacteria and can be considered for pretreating cultures to enhance these desirable attributes. This is a step toward developing a future generation of more efficient probiotics.

http://dx.doi.org/10.3168/jds.2012-5842.

Effect of genetic type and casein haplotype on antioxidant activity of yogurts during storage. By Perna et al., page 3435. Yogurt is an ancient food widespread in daily use. It is considered a healthy food because of its high digestibility and bioavailability of its protein, energy, and calcium. Lactic acid bacteria are able to hydrolyze casein, releasing a large number of peptides and amino acids with varying biological activity, including antioxidative, antithrombotic, and antimicrobial activities. The antioxidant peptides play a vital role in the maintenance of antioxidant defense systems by preventing the formation of free radicals or scavenging free radicals, which induce oxidative damage to biomolecules. This work highlights the effect of genetic type and casein haplotype on the antioxidant activity of yogurt. Therefore, it is possible to choose the most suitable haplotype to be used for the manufacture of yogurts.

http://dx.doi.org/10.3168/jds.2012-5859.

Modeling the growth of Listeria monocytogenes in mold-ripened cheeses. By Lobacz et al., page 3449. Predictive microbiology is a subdiscipline of food microbiology that aims to generate predictive models mainly for foodborne pathogens on the assumption that the response of microorganisms to environmental factors is reproducible and that it is possible to predict the behavior of microorganisms in food on the basis of past experiments and observations. The goodness-of-fit of generated predictive models describing the growth of Listeria monocytogenes in mold-ripened cheeses was evaluated.

http://dx.doi.org/10.3168/jds.2012-5964.

Comparing bacterial membrane interactions and antimicrobial activity of porcine lactoferricin-derived peptides. By Wang et al., page 3471. We designed and synthesized several tryptophan-rich analogs of the 20-residue porcine lactoferricin LFP-20. A comparison of the biological properties of analogs and template showed that analogs exhibited stronger antimicrobial activity than LFP-20 as well as a balance between antimicrobial activity and cytotoxicity. Based on the interactions between peptides and the cytoplasmic membrane, 3 analogs exhibited lethality due to their ability to disrupt membranes, allowing the movement of large intracellular components such as calcein. An increased understanding of the various effects of peptide action on bacteria, particularly those involving peptide analogs with low minimum inhibitory concentrations, will allow the design of more potent and less toxic antimicrobial peptides, which can be used as templates for developing new peptide antibiotics to treat microbial infection.

http://dx.doi.org/10.3168/jds.2012-6104.

Milk fat globule membrane isolated from buttermilk or whey cream and their lipid components inhibit infectivity of rotavirus in vitro. $B y$ Donovan et al., page 3488. Bovine milk appears to be a rich source of lipids with anti-infective properties. Lipid components associated with milk fat globule membrane (MFGM) appear to contribute, in large part, to the anti-rotavirus activity associated with the bovine MFGM. Given the large quantities of buttermilk from butter production and of whey cream generated from cheese production, this work supports efforts to explore valueadded uses for MFGM isolated from these sources.

http://dx.doi.org/10.3168/jds.2012-6122.

Evaluation of the mineral content of infant formulas consumed in Brazil. By Barin et al., page 3498. Starting and follow-up infant formulas consumed in Brazil were evaluated with respect to their contents of $\mathrm{Ca}, \mathrm{Cu}, \mathrm{Fe}, \mathrm{K}, \mathrm{Mg}, \mathrm{Mn}, \mathrm{Na}$, and $\mathrm{Zn}$. The results were compared with the producers' label declarations and levels proposed by Codex Alimentarius and Brazilian standards. Large differences between experimental and producer data (up to 68\%) were found for trace ele- 
ments, particularly for $\mathrm{Cu}$ and $\mathrm{Zn}$. Three commercial brands presented levels of $\mathrm{Ca}, \mathrm{K}$, and $\mathrm{Zn}$ outside the recommended values.

http://dx.doi.org/10.3168/jds.2012-6268.

Factors influencing the stability of freeze-dried stress-resilient and stress-sensitive strains of bifidobacteria. By Celik and O'Sullivan, page 3506. Freeze-drying is frequently used for the preservation of probiotics, especially bifidobacteria cultures that may be very sensitive to stress. This study compares the effects of freeze-drying and subsequent storage for a stress-resilient commercial bifidobacteria culture and a stress-sensitive intestinal strain of Bifidobacterium longum. The commercial culture retained viability over a wide range of conditions, whereas viability of the stress-sensitive culture could only be adequately maintained using optimized conditions. This indicates that intestinal strains, that have not been altered by extensive growth in pure culture, can be used for probiotic applications if optimized conditions are used.

http://dx.doi.org/10.3168/jds.2012-6327.

Long-term detection of Mycobacterium avium subspecies paratuberculosis in individual and bulk tank milk from a dairy herd with a low prevalence of Johne's disease. By Khol et al., page 3517. Mycobacterium avium ssp. paratuberculosis, causing Johne's disease in ruminants, is shed with the milk of infected cows, contributing to the discussion of a possible link to Crohn disease in humans. The aim of the study was to investigate the level of shedding of the bacterium into milk from cows with subclinical Johne's disease. The bacterium was only shed in milk for limited periods in a small proportion of subclinically infected cows. This finding indicates that milk from herds with subclinical Johne's disease poses a limited risk for human consumption of Mycobacterium avium ssp. paratuberculosis.

http://dx.doi.org/10.3168/jds.2012-6466.

Oral administration of Lactobacillus delbrueckii subspecies bulgaricus OLL1073R-1 suppresses inflammation by decreasing interleukin-6 responses in a murine model of atopic dermatitis. By Kano et al., page 3525. The oral intake of Lactobacillus species can provide beneficial effects to the host by modulating the immune response. We investigated the effect of Lactobacillus delbrueckii ssp. bulgaricus OLL1073R-1 (OLL1073R-1) on the development of atopic dermatitis in a murine model. The oral intake of heat-killed OLL1073R-1 cells inhibited both the development of dermatitis and the elevation of an acute inflammatory marker, serum amyloid A. We also found that interleukin-6 (IL-6) played an essential role in the development of dermatitis in the murine model of atopic dermatitis, and that OLL1073R-1 inhibited dermatitis, at least in part, by suppressing the IL-6 response.

http://dx.doi.org/10.3168/jds.2012-6514.

Isolation and characterization of Staphylococcus aureus strains from a Paso del Norte dairy. By Matyi et al., page 3535. The aim of this study was to determine if methicillin-resistant Staphylococcus aureus (MRSA) strains could be identified in the milk of dairy cattle in a Paso del Norte dairy. Using physiological and PCR-based identification schemes, 40 Staph. aureus strains were isolated from 133 milk samples analyzed. This investigation also included the production of draft genome sequences of a MRSA and a methicillin-susceptible isolate. Genomic analysis demonstrated that strains H29 and PB32 represent novel clones of sequenced human- or bovine-related strains of Staph. aureus.

http://dx.doi.org/10.3168/jds.2013-6590.

Short communication: Heat resistance of Escherichia coli strains at different subpasteurization conditions. By Peng et al., page 3543. In this study, different thermization (a mild heat treatment of raw milk) processes, reflecting commercial conditions, were tested for their efficiency in reducing Escherichia coli strains in a pilot-plant pasteurizer. Three of 9 E. coli strains showed an increased thermotolerance.

http://dx.doi.org/10.3168/jds.2012-6174.

Short communication: Jenny milk as an inhibitor of late blowing in cheese: A preliminary report. By Cosentino et al., page 354\%. Lysozyme extracted from hen egg white is widely used as a antimicrobial agent in cheese. Its use is becoming less attractive, however, as recent studies have documented severe allergic reactions in egg consumers. For this reason, we evaluated the possibility of using, as a substitute, lysozyme obtained from jenny milk, a nonallergenic source that contains high quantities of this natural preservative. http://dx.doi.org/10.3168/jds.2012-6225.

Short communication: Peptide profiling in cheeses packed using different technologies. By Sánchez-Rivera et al., page 3551. Peptide profiles of vacuum-packaged (VP) and sliced modified-atmosphere packaged (MAP) cheeses were compared after their analysis and peptide identification by HPLC-tandem mass spectrometry. In general, peptides evolved similarly in both cheeses during their shelf-life, although slight differences were found between VP and MAP cheeses, mainly at the quantitative level. Regardless of packaging technology, both cheeses were rich in peptide 
sequences previously reported as possessing potential bioactivity.

http://dx.doi.org/10.3168/jds.2012-6302.

Short communication: Phenotypic and genetic diversity of wild Lactococcus lactis isolated from traditional Pecorino cheeses of Tuscany. By Turchi et al., page 3558. Lactococci of traditional Pecorino cheeses from different regions of Tuscany were characterized via multilocus sequence typing and technological testing, demonstrating a straightforward method for describing the diversity of important dairy bacteria in great detail and providing evidence for the microbial effects on regional differences in artisanal cheese.

http://dx.doi.org/10.3168/jds.2012-6518.

Effect of the level of maternal energy intake prepartum on immunometabolic markers, polymorphonuclear leukocyte function, and neutrophil gene network expression in neonatal Holstein heifer calves. By Osorio et al., page 3573. Immune function, metabolism, and neutrophil gene expression during the first week of life were assessed in calves born to cows fed a controlled-energy diet (1.24 $\mathrm{Mcal} / \mathrm{kg}$ of dry matter) during the dry period or this diet followed by a moderate-energy $(1.47 \mathrm{Mcal} / \mathrm{kg})$ diet during the last $21 \mathrm{~d}$ prepartum. Prepartum moderateenergy feeding was associated with an alteration of the innate-immune response in calves, as reflected by changes in neutrophil gene expression. This response was further supported by the greater neutrophil phagocytic capacity of the calves after consuming colostrum. Data provide potential avenues for further research in designing supplements to fortify colostrum to enhance immunologic capabilities of the neonatal calf.

http://dx.doi.org/10.3168/jds.2012-5759.

Comparison of innate immune responses and somatotropic axis components of Holstein and Montbéliarde-sired crossbred dairy cows during the transition period. By Mendonça et al., page 3588. Increased relationship and inbreeding compromise health of livestock. Polymorphonuclear cells (PMNL) from Holstein cows exhibited reduced expression of CD18, an adhesion molecule responsible for migration of PMNL to the site of inflammation. Intensity of phagocytosis of PMNL from Holstein cows was reduced on the day of calving compared with that $7 \mathrm{~d}$ before and after calving, but this pattern of phagocytosis was not observed in crossbred cows. Dairy cows are known to have uncoupling of the somatotropic axis during early lactation that ensures continued milk production during periods of negative energy balance. Both Holstein and crossbred cows had uncoupling of the somatotropic axis, but Holstein cows appeared to be less sensitive to the negative feedback of insulin-like growth factor-1 on growth hormone secretion.

http://dx.doi.org/10.3168/jds.2012-5804.

Identification of hepatic biomarkers for physiological imbalance of dairy cows in early and mid lactation using proteomic technology. By Moyes et al., page 3599. Predicting physiological imbalance (PI), a situation in which physiological parameters deviate from the normal, is needed to reduce disease risk and improve production and reproduction performance of cows. Quantitative profiling in liver using liquid chromatography-tandem mass spectrometry identified potential biomarkers of PI for cows in early and mid lactation. These results lay a foundation for future research focused on new management strategies that can identify cows at risk for disease during lactation. http://dx.doi.org/10.3168/jds.2012-5900.

\section{Evaluation of PCR electrospray-ionization mass} spectrometry for rapid molecular diagnosis of bovine mastitis. By Perreten et al., page 3611. Milk samples from cows suffering from mastitis were analyzed for the presence of pathogens using PCR electrospray-ionization mass spectrometry (PCR/ESI-MS) compared with standard culture methods. Concurrent identification of the primary mastitis pathogens was obtained for $64 \%$ of samples. In addition, PCR/ESI identified pathogens in samples that were negative by culture. Most importantly, PCR/ESI-MS revealed the presence of the methicillin-resistance gene mecA and a metallo- $\beta$-lactamase gene in milk. We show that PCR/ ESI-MS has significant potential as an important rapid screening method in the diagnosis of bovine mastitis and can be used to trace the spread of resistance genes in milk. http://dx.doi.org/10.3168/jds.2012-6124.

Metritis in dairy cows: Risk factors and reproductive performance. By Giuliodori et al., page 3621. The objectives of this study were to assess the risk factors for metritis, the effects of metritis on milk yield and reproductive performance, and the efficacy of ceftiofur therapy in 303 Holstein dairy cows. Dystocia, retention of placenta, and negative energy balance increased the risk for metritis. Puerperal metritis reduced both milk production and reproductive performance. Finally, cure rate was not affected by ceftiofur, but it increased with postpartum days $(2.6 \% / \mathrm{d})$ and was 2 times higher for cows with clinical metritis than for those with puerperal metritis.

http://dx.doi.org/10.3168/jds.2012-5922.

Effects of rubber flooring during the first 2 lactations on production, locomotion, hoof health, immune functions, and stress. By Eicher et al., 
page 3639. Rubber was compared with concrete flooring during the first and second lactations. Important production measures, such as milk fat and protein, were less for cows on concrete. The number of hoof therapies required was greater for those housed on concrete, and cows housed on concrete had worse locomotion in the second lactation. Cows housed on concrete had greater white blood cell counts, particularly in the second lactation, indicating an ongoing inflammation. Additionally, greater expression of inflammatory cell mediators (cytokines) confirmed the presence of a chronic inflammation. These data support the use of rubber flooring for cow health and comfort.

http://dx.doi.org/10.3168/jds.2012-6049.

Priming the cow for lactation by rapeseed supplementation in the dry period. By Damgaard et al., page 3652. High-producing dairy cows have a significant increase in energy requirement for milk production in early lactation and mobilize body reserves, resulting in increased risk of production decline and development of health disorders. Feeding the cows a supplement of oilseed (rapeseed) in the dry period did not benefit milk production but the milk fat concentration decreased. The intake of oilseeds had positive effects on the metabolism of fatty acids. These results indicate that oilseed in the dry period may improve the dairy cow's ability to mobilize fatty acids and thereby the health status in early lactation.

http://dx.doi.org/10.3168/jds.2012-6055.

Milk haptoglobin, milk amyloid $\mathrm{A}$, and $\mathrm{N}$-acetyl$\beta$-D-glucosaminidase activity in bovines with naturally occurring clinical mastitis diagnosed with a quantitative PCR test. By Kalmus et al., page 3662. The objective of the study was to investigate associations between quantitative bacteriological results from a real-time PCR test and concentrations of acute phase proteins (APP) and $N$-acetyl- $\beta$-D-glucosaminidase (NAGase) activity in milk in naturally occurring clinical mastitis. The quantity of bacterial DNA in the milk sample was associated with concentrations of APP and NAGase activity in the milk. These indicators reflect the inflammatory reaction in the mammary gland, and their concentrations increased with increasing severity of mastitis. Concentrations of APP and NAGase activity in the milk differed significantly between different mastitis-causing bacterial species. Indicators of inflammation in the milk such as APP and NAGase activity may be useful to support bacteriological diagnosis of mastitis.

http://dx.doi.org/10.3168/jds.2012-6177.

The effect of somatic cell count data adjustment and interpretation, as outlined in European Union legislation, on herd eligibility to supply raw milk for processing of dairy products. $B y$
More et al., page 3671. Somatic cell count (SCC) limits are a key component of national and international regulation for milk quality. As outlined in European Union legislation, several methods of adjustment and interpretation of herd SCC data are applied before assessing the eligibility of herds to supply raw milk for processing of dairy products for human consumption. This study examines the effect of data adjustment and interpretation on herd eligibility and on-farm mastitis control.

http://dx.doi.org/10.3168/jds.2012-6182.

Effects of meloxicam on milk production, behavior, and feed intake in dairy cows following assisted calving. By Newby et al., page 3682. Little research has been done to investigate the management of postcalving pain in dairy cattle. Our objective was to investigate the effects of the analgesic meloxicam given $24 \mathrm{~h}$ following assisted calving. This study failed to show any significant effects of treatment on feed intake, milk production, blood metabolites, or health events, but meloxicam treatment did increase the time spent at the feed bunk, compared with the placebo treatment. Further research is needed to investigate means of assessing and reducing pain associated with calving.

http://dx.doi.org/10.3168/jds.2012-6214.

Associations of risk factors with somatic cell count in bulk tank milk on organic and conventional dairy farms in the United States. By Cicconi-Hogan et al., page 3689. Because the organic dairy industry is one of the fastest growing agricultural sectors in the United States, research on the best management practices is especially useful. The goal of this study was to evaluate somatic cell count on organic and conventional dairy farms and determine which management and herd characteristics were most influential. An important finding was that farms that used more intensive management strategies tended to have lower somatic cell counts.

http://dx.doi.org/10.3168/jds.2012-6271.

Applicability of day-to-day variation in behavior for the automated detection of lameness in dairy cows. By de Mol et al., page 3703. Lameness is a major problem in dairy husbandry. A lameness detection model was developed based on day-to-day variation in activity measurements (or milk yield and concentrates intake). This model was validated on 2 data sets. The first data set contained 100 cows over almost 2 yr with 85 lameness cases; it was used for model development. The second data set contained 100 cows over 4 mo with 15 cases and was used for validation. The results for both data sets were comparable. Overall, $85.5 \%$ of the lameness cases were detected and $88.8 \%$ of the nonlame cows were not alerted.

http://dx.doi.org/10.3168/jds.2012-6305. 
Sire predicted transmitting ability for conformation and yield traits and previous lactation. By Oikonomou et al., page 3713. The objectives of this study were to evaluate the effects of certain foot lesions on subsequent incidence in later lactations; to evaluate their effect on cows' survivability; and to evaluate their associations with milk production. We demonstrated high repeatability for all investigated lesions; cows affected in previous lactations were at higher risk of being affected again in future lactations. Additionally, we investigated the role of sires' predicted transmitting ability for various production and conformation traits as risk factors for their daughters' foot lesions. Several production and conformation traits were significantly associated with the incidence of foot lesions.

http://dx.doi.org/10.3168/jds.2012-6308.

Early host response in the mammary gland after experimental Streptococcus uberis challenge in heifers. By de Greeff et al., page 3723. Streptococcus uberis is a causative agent of bovine mastitis, causing economic losses in the dairy industry. We examined host responses during acute inflammation after experimental challenge with capsulated Strep. uberis in heifers, using microarray, quantitative PCR, and immunohistochemistry. Microarrays showed that 239 host genes were differentially expressed between infected and control quarters, including genes involved in pathogen recognition, chemoattraction, and bactericidal activity. Immunohistochemistry showed that mammary cells play an active role in the early host response to intramammary challenge. Insight into host responses could help to design immunomodulatory therapies to dampen inflammation after (early) diagnosis of Strep. uberis mastitis.

http://dx.doi.org/10.3168/jds.2012-6320.

Hepatic mRNA expression of acid labile subunit and deiodinase 1 differs between cows selected for high versus low concentrations of insulin-like growth factor I in late pregnancy. By Piechotta et al., page 3737. A more detailed understanding of the crucial metabolic adaptation in late pregnancy is needed to promote health in dairy cows. The somatotropic axis is regarded as a key driver of metabolism and this paper describes the metabolic and endocrine differences between animals selected based on their total insulin-like growth factor (IGF-I) plasma concentration by using one blood sample collected in late pregnancy. The differences in IGF-I concentration may be attributed to differences in hepatic production of acid labile subunit. Moreover, thyroid hormone metabolism differs between cows with lower versus higher total IGF-I concentrations.

http://dx.doi.org/10.3168/jds.2012-6341.
Function of milk polymorphonuclear neutrophil leukocytes in bovine mammary glands infected with Corynebacterium bovis. By Blagitz et al., page 3750. This study investigated the function of milk polymorphonuclear neutrophil leukocytes (PMNL) from healthy and Corynebacterium bovis-infected mammary glands. A higher percentage of milk PMNL, a lower percentage of PMNL apoptosis, and higher PMNL viability were observed in milk from $C$. bovis-infected quarters compared with uninfected quarters. Furthermore, a higher percentage of PMNL that produced intracellular reactive oxygen species were found in milk from $C$. bovis-infected quarters. No differences were observed in the phagocytosis of Staphylococcus aureus or in the expression of molecules involved in the transepithelial migration of milk PMNL. Thus, mastitis caused by $C$. bovis may offer protection against intramammary infections by other pathogens. http://dx.doi.org/10.3168/jds.2012-6370.

Herd-level risk factors for hock injuries in freestall-housed dairy cows in the northeastern United States and California. By von Keyserlingk et al., page 3758. Hock injuries in high-producing dairy cows varied in relation to design and management of freestall barns in 2 regions of the United States. In the northeastern United States (New York, Vermont, and Pennsylvania), use of deep-bedded stalls, clean bedding, access to pasture, and avoiding the use of automatic scrapers for manure removal reduced hock injuries. In California (where all herds assessed used deep bedding), injuries were less common on farms with better stall management.

http://dx.doi.org/10.3168/jds.2012-6389.

Milking efficiency for grazing dairy cows can be improved by increasing automatic cluster remover thresholds without applying premilking stimulation. By Edwards et al., page 3766. Increasing automatic cluster remover thresholds up to $0.8 \mathrm{~kg} /$ min can be used effectively in a pasture-based system without premilking stimulation to improve milking efficiency (cows milked per operator per hour), without compromising milk yield, milk composition, or indicators of udder health. In comparison, premilking treatments did not improve milking efficiency and provided no benefit to milk yield, milk composition, or indicators of udder health. Thus, clusters should be attached immediately to improve cluster utilization.

http://dx.doi.org/10.3168/jds.2012-6394.

Measurement of fecal glucocorticoid metabolites and evaluation of udder characteristics to estimate stress after sudden dry-off in dairy cows with different milk yields. By Bertulat et al., 
page 3774. Drying off is an important management tool in the dairy industry. The daily milking routine has to be interrupted before calving in order to regenerate the udder. In high-yielding dairy cows, the first week after dry-off is critical as udders are swollen, firm, and at risk for infection. Cows often show signs of discomfort. We studied udder pressure and stress hormones before and after dry-off and their relationships. Our data demonstrated that udder pressure and stress hormone concentration increase after dry-off. A relationship existed between high milk yield and high stress levels. Current dry-off procedures, especially for high-yielding cows, need to be reconsidered.

http://dx.doi.org/10.3168/jds.2012-6425.

Effect of timing of initiation of resynchronization and presynchronization with gondaotropinreleasing hormone on fertility of resynchronized inseminations in lactating dairy cows. By Lopes et al., page 3788. Lactating dairy cows were submitted to a resynchronization protocol either $32 \pm 3$ or $39 \pm 3 \mathrm{~d}$ after artificial insemination (AI) and were randomized within these treatments to receive a presynchronization treatment with gonadotropin-releasing hormone $(\mathrm{GnRH})$ injection $7 \mathrm{~d}$ before the initiation of the resynchronization protocol or to serve as untreated controls. Timing of initiation of resynchronization after AI did not affect fertility, whereas greater fertility was observed for cows presynchronized with GnRH. Based on these results, cows can be presynchronized with GnRH before a nonpregnancy diagnosis and submitted to a protocol that improves fertility to timed AI.

http://dx.doi.org/10.3168/jds.2012-6429.

Effect on quarter milk somatic cell count and antimicrobial susceptibility of Staphylococcus rostri causing intramammary infection in dairy water buffaloes. By Locatelli et al., page 3799. This paper is the first to describe the presence of Staphylococcus rostri in the milk of dairy buffaloes. The relevance for udder health of Staph. rostri intramammary infections (IMI) relative to other mastitis pathogens, including other coagulase-negative staphylococci (CNS) species, and the antimicrobial resistance pattern in dairy water buffaloes were explored. Staphylococcus rostri and other CNS increased the quarter milk somatic cell count (qSCC) in a similar manner to Streptococcus species. No differences in qSCC were observed between Staph. rostri IMI and other CNS IMI. All Staph. rostri isolates were highly susceptible to the most commonly used antimicrobials.

http://dx.doi.org/10.3168/jds.2012-6275.

Follicular populations and luteal function in dairy heifers treated with a controlled internal drug release insert for $14 \mathrm{~d}$ as a method to synchronize the estrous cycle before prostaglandin
$\mathbf{F}_{2 \alpha}$ treatment and artificial insemination. $B y$ Escalante et al., page 3806. Progesterone-containing controlled internal drug release (CIDR) inserts are administered for $14 \mathrm{~d}$ to synchronize an estrous cycle before prostaglandin $\mathrm{F}_{2 \alpha}\left(\mathrm{PGF}_{2 \alpha}\right)$ is administered for timed AI in beef cows and beef heifers. The program was recently shown to be efficacious in dairy heifers but the ovarian response to treatment was not reported. We found that treating dairy heifers with a CIDR insert for $14 \mathrm{~d}$ effectively synchronized an estrous cycle. The CIDR-treated heifers had large, functional corpora lutea and large follicles at the time of subsequent $\mathrm{PGF}_{2 \alpha}$ treatment (16 d after CIDR removal).

http://dx.doi.org/10.3168/jds.2012-6474.

Reducing the duration between gonadotropinreleasing hormone (GnRH) and prostaglandin $F_{2 \alpha}$ in the Ovsynch protocol to 6 days improved ovulation to second GnRH, but inclined to reduce fertility. By Yilmazbas-Mecitoglu et al., page 381\%. The aim of this study was to test Ovsynch (OVS7, a common synchronization program) against modified Ovsynch [OVS6, a shortened Ovsynch program by decreasing the interval between first gonadotropin-releasing hormone $(\mathrm{GnRH})$ and prostaglandin $\mathrm{F}_{2 \alpha}\left(\mathrm{PGF}_{2 \alpha}\right)$ to $6 \mathrm{~d}$ ] protocols on pregnancy rate in cyclic dairy cows. The response to the second GnRH of Ovsynch was higher in OVS6 than OVS7. Pregnancy rate tended to be lower in OVS6 than in OVS7. Although OVS6 protocol increased the ovulatory response to second GnRH of Ovsynch, unexpectedly it tended to reduce fertility in cyclic lactating dairy cows.

http://dx.doi.org/10.3168/jds.2012-6496.

Conjugated linoleic acid-induced milk fat depression in lactating ewes is accompanied by reduced expression of mammary genes involved in lipid synthesis. By Hussein et al., page 3825. The trans-10, cis-12 conjugated linoleic acid (CLA) isomer induces milk fat depression (MFD) in lactating cows but the mechanisms are not fully understood. We investigated the use of sheep as a model for CLA-induced MFD in ewes that received CLA supplement for 10 wk of lactation. As in dairy cows, ewes decreased milk fat yield and proportions of de novo synthesized milk fatty acids, and mRNA abundance of key enzymes and transcription factors involved in lipid synthesis were down-regulated. We conclude that CLA-induced MFD in lactating ewes is similar to that in cows; hence, ewes can be used as an effective model to further investigate MFD.

http://dx.doi.org/10.3168/jds.2013-6576.

Jersey calf performance in response to highprotein, high-fat liquid feeds with varied fatty acid profiles: Blood metabolites and liver gene expression. By Swank et al., page 3845. The objec- 
tive was to determine whether altering the fatty acid profile of calf milk replacer by increasing the amount of medium-chain fatty acids with coconut oil in place of edible lard would alter liver lipid infiltration, liver gene expression, and blood metabolites when fed to Jersey calves. No changes in liver lipid infiltration or gene expression were noted. Minor differences in blood metabolite concentrations were observed. Medium-chain fatty acids in preruminant Jersey calf diets may not be as biologically important as hypothesized.

http://dx.doi.org/10.3168/jds.2012-6100.

The effect of starch-, fiber-, or sugar-based supplements on nitrogen utilization in grazing dairy cows. By Higgs et al., page 385\%. Nitrogen utilization in temperate grazing systems is low because of the high crude protein concentration in well-fertilized and managed pastures. The objective of this study was to compare the relative importance of reducing $\mathrm{N}$ intake with increasing productive $\mathrm{N}$ output using starch-, fiber-, or sugar-based supplements for improving $\mathrm{N}$ utilization in grazing cows. Results indicate that controlling $\mathrm{N}$ intake is the most important factor in improving $\mathrm{N}$ utilization, although, at equal metabolizable energy intake, a small improvement was observed with provision of dietary starch.

http://dx.doi.org/10.3168/jds.2012-6117.

Revised digestive parameter rates for the Molly cow model. By Hanigan et al., page 3867. Data on the rate of bovine volatile fatty acid production from several publications were used to evaluate the accuracy and precision of predictions by the Molly cow model. The results indicated that the model poorly predicted net volatile fatty acid production rates. Moreover, the lack of consideration of interconversions among volatile fatty acids may be contributing to the errors of prediction. Thus, consideration of interconversions driven by thermodynamics may improve predictions of net volatile fatty acid production rates.

http://dx.doi.org/10.3168/jds.2012-6183.

Alkalinizing effect of $\mathrm{NaHCO}_{3}$ with and without
glucose when administered orally to euhydrated
neonatal dairy calves. By Grünberg et al., page 3895 .
The use of oral electrolyte solutions is well established
as standard treatment in diarrheic calves. These solu-
tions are composed of glucose, sodium, and alkalinizing
agents as the main ingredients. Although our current
understanding of acid-base physiology and mechanisms
of intestinal glucose and sodium absorption indicate
that glucose has the potential to improve the alkalin-
izing effect oral electrolyte solutions, this effect has not
yet been studied. Glucose contained in the electrolyte
solutions did not affect the alkalinizing effect of these
solutions. Our findings contribute to a better under- standing of the mechanism of action of oral electrolyte solutions in calves.

http://dx.doi.org/10.3168/jds.2012-6202.

Effects of urea formaldehyde condensation polymer treatment of flaxseed on ruminal digestion and lactation in dairy cows. By Hawkins et al., page 390\%. Flaxseed is rich in a-linolenic acid, little of which survives ruminal biohydrogenation. The objective of this study was to evaluate the effects of heating and urea formaldehyde condensation polymer (UFCP) treatment on ruminal degradation of flaxseed, and to assess the production responses to UFCP treatment versus heating alone when flaxseed was fed to lactating dairy cows. Both treatments slowed ruminal degradation of flaxseed, but plasma concentration and milk secretion of a-linolenic acid was not increased by UFCP compared with heating. These data indicate that UFCP treatment was not more effective than heating flaxseed for altering the a-linolenic acid content of plasma or milk.

http://dx.doi.org/10.3168/jds.2012-6207.

Effects of transient changes in silage dry matter concentration on lactating dairy cows. By McBeth et al., page 3924. We hypothesized that a transient inclusion of wetted silage (to mimic feeding silage that was rained upon) in a diet would negatively affect production. A consistent diet was fed for most of the period except that water was added to the silage of 2 treatments during two 3-d bouts. Milk production was not different from control when cows were fed wetted silage if inclusion rates were adjusted to maintain diet composition on a dry basis. When cows were fed wetted silage and the diet was not adjusted, milk yield increased. Rebalancing a diet changed by water addition to silage was not necessary.

http://dx.doi.org/10.3168/jds.2012-6330.

Meta-analysis of factors that affect the utilization efficiency of phosphorus in lactating dairy cows. By Klop et al., page 3936. Environmental concerns and expected global phosphorus $(\mathrm{P})$ scarcity have increased the importance of improved efficiency of $\mathrm{P}$ use in dairy farming systems. A meta-analysis based on literature data was conducted to estimate the effect of nutritional and animal factors on efficiency of $\mathrm{P}$ utilization in lactating dairy cattle. Results presented here can be used to estimate $\mathrm{P}$ in feces and milk based on commonly measured dietary and milk variables, but could also be used in further development of mechanistic models on $\mathrm{P}$ metabolism in lactating dairy cattle. http://dx.doi.org/10.3168/jds.2012-6336.

Growing dairy heifers prefer supplementary long straw when fed a nutrient-dense ration 
in a limited amount. By Greter et al., page 3950. The objective of this study was to determine whether limit-fed heifers would choose to consume long, rather than short, particles of a low-nutritive feedstuff to ameliorate rumen function and meet foraging needs. Ten Holstein dairy heifers were exposed to each of 2 treatments: provision of (1) long, or (2) short oat straw, in addition to a limit-fed total mixed ration; straw types were also offered as a choice. Results indicated that providing limit-fed dairy heifers with straw of either length increased intake similarly, whereas heifers spent more time consuming long straw, and greatly preferred long straw, when given the choice.

http://dx.doi.org/10.3168/jds.2013-6625.

Genome-wide association analysis identifies loci for left-sided displacement of the abomasum in German Holstein cattle. By Mömke et al., page 3959. Left-sided displacement of the abomasum (LDA) is a frequent and economically important disease in dairy cows around parturition. Culling rate is significantly increased in cows affected by this disease. In this study, we performed a genome-wide association analysis using the Illumina Bovine SNP50 beadchip (Illumina Inc., San Diego, CA) and identified genetic loci significantly associated with left-sided displacement of the abomasum in German Holstein cows. Pathway analyses identified putative candidate genes clustering mainly for candidate LDA pathways of calcium metabolism and insulin-dependent diabetes mellitus.

http://dx.doi.org/10.3168/jds.2012-5679.

Genetic parameters for natural antibodies and associations with specific antibody and mastitis in Canadian Holsteins. By Thompson-Crispi et al., page 3965. The goal of this study was to determine if natural antibodies in the serum of Holstein dairy cows could be used as a predictor of enhanced health. Previous work has shown that cows with high specific antibody responses have a lower occurrence of many diseases, including mastitis. Natural antibodies were measured in a single serum sample, without prior immunization, against keyhole limpet hemocyanin and correlated with mastitis. Natural antibodies were moderately heritable and associated with a decreased risk for mastitis.

http://dx.doi.org/10.3168/jds.2012-5919.

Genetic and environmental info in goat milk Fourier transform infrared spectra. By Dagnachew et al., page 3973. The study examined the genetic and environmental components of goat milk Fourier transform infrared (FTIR) spectra. Heritabilities of the spectral variables were between 0.018 and 0.408 . High to moderate heritabilites were observed particularly in spectral regions related to major milk components (fat, lactose, and protein). Not all spectral regions were genetically determined; however, some regions were highly influenced by herd-test-day variation. The observed environmental and herd-test-day variabilities of the spectra suggest that FTIR spectra have potential to be used as a herd management monitoring tool. http://dx.doi.org/10.3168/jds.2012-5972.

Prediction of clinical mastitis outcomes within and between environments using whole-genome markers. By Haugaard et al., page 3986. Whole-genome marker-assisted predictions were performed for 1,126 bulls within and between environments defined according to pathogen status. The analyzed trait was daughter yield deviations for clinical mastitis. The aim was to investigate whether training the statistical model in one environment and testing it in another affected the predictive ability compared with training and testing the model in the same environment. No evidence of genotype by environment interaction was found. However, low rank correlations between estimated marker effects may indicate that markers are pathogen-specific. http://dx.doi.org/10.3168/jds.2012-6133.

Development of a genetic evaluation for body condition score for Canadian Holsteins. By Loker et al., page 3994. Longitudinal body condition score is collected by Valacta (a Canadian milk recording agency) from Québec herds. Traits recorded nationwide that are genetically correlated with Valacta's body condition score are required for a national genetic evaluation of longitudinal body condition score. Holstein Canada records body condition score and other type traits once at classification for herds across Canada. Different methods of calculating a national genetic evaluation of body condition score were compared. Using Holstein Canada's body condition score, rather than Valacta's body condition score, was the most efficient method of genetically evaluating the trait.

http://dx.doi.org/10.3168/jds.2012-6148.

The mathematical modelling of the lactation curve for dairy traits of the donkey (Equus asinus). By Bordonaro et al., page 4005. Lactation curves for milk yield, fat and protein percentages, and somatic cell score of 46 Ragusano breed jennies were modeled using 3 mathematical functions. The general pattern of the donkey lactation curve is similar to that reported for the main dairy ruminant species. Youngest jennies tended to have lower production peaks and higher lactation persistency. A large variability in individual patterns was observed.

http://dx.doi.org/10.3168/jds.2012-6180.

Direct and maternal genetic relationships between calving ease, gestation length, milk production, fertility, type, and lifespan of HolsteinFriesian primiparous cows. By Eaglen et al., page 
4015. It would be of economic benefit to the UK dairy cattle industry to reduce the number of difficult calvings by genetic selection. However, the genetic relationships between calving ease and other dairy traits are unknown. This information is essential for the inclusion of calving ease in national breeding indices. Our results show significant genetic correlations between firstlactation calving ease and other important dairy traits. Furthermore, direct and maternal genetic correlations differ, which needs to be taken into account. Gestation length, a trait assumed related to the calving process, also shows significant genetic correlations with the remaining traits. Results indicate that gestation length is best used as an indicator trait for lowly heritable calving traits such as calving ease, rather than as a novel selection trait.

http://dx.doi.org/10.3168/jds.2012-6229.

A genetic study of mortality in Danish Jersey heifer calves. By Norberg et al., page 4026. Mortality of Jersey heifer calves the first $180 \mathrm{~d}$ after birth is relatively high compared wth that of other dairy breeds. The aim of this study was to investigate the genetic basis of this trait in Danish Jerseys. Heritability estimates were low; however, the best and worst sires differed by around $8 \%$ mortality. This demonstrates that sufficient genetic variation exists in this trait to consider its inclusion in breeding programs. Over the last $20 \mathrm{yr}$, the genetic trend of mortality of Jersey heifer calves has not demonstrably changed.

http://dx.doi.org/10.3168/jds.2012-5659.

Changes in teat-end hyperkeratosis after installation of an individual quarter pulsation milking system. By Sterrett et al., page 4041. Overmilking may increase teat-end hyperkeratosis, a callous ring around the teat end that forms after repeated or prolonged milkings. In turn, increased hyperkeratosis may increase mastitis incidence. The objective of this study was to examine changes in teat-end hyperkeratosis in a herd transitioning from a standard pulsation system to an individual quarter pulsation milking system with potential for decreasing overmilking. The individual quarter pulsation milking system decreased hyperkeratosis in Holstein cows.

http://dx.doi.org/10.3168/jds.2012-6069.

Development of protocols to evaluate in-line mastitis-detection systems. By Kamphuis et al., page 404\%. Mastitis detection systems should assist farmers with (1) finding cows with clinical mastitis, (2) finding cows with a high milk cell count, and (3) making individual cow management decisions regarding udder health at the end of the lactation. Because farmers do not have access to objective information about the performance of different automated mastitis detection systems, evaluation protocols and performance targets are required. This study provides a further step in the development of agreed evaluation protocols to ensure that different systems can be evaluated comparatively, enabling farmers to make more informed decisions regarding investment. They should also assist technology providers to improve current, or develop new, mastitis detection systems that better meet farmers' needs.

http://dx.doi.org/10.3168/jds.2012-6190.

Evaluating expansion strategies for startup European Union dairy farm businesses. By McDonald et al., page 4059. Six alternative expansion strategies for new dairy farm businesses were evaluated using a stochastic whole-farm simulation model and incorporating multiple financial stability and risk indicators over a 15-yr period. Within the context of European Union milk quotas until 2015, the most attractive expansion strategy was to increase cow numbers while avoiding super levy fines using once-a-day milking techniques, increasing to the full capacity of the dairy farm when milk quotas are removed. Our results also indicated that dairy farms that remain static will experience a significant reduction in farm profit due to production cost inflation.

http://dx.doi.org/10.3168/jds.2012-6365.

Requirements for zero energy balance of nonlactating, pregnant dairy cows fed fresh autumn pasture are greater than currently estimated. By Mandok et al., page 4070. Over 2 yr, 4 cohorts of nonlactating, pregnant dairy cows (total $\mathrm{n}=53$ ) were fed autumn pasture to determine the amount of energy necessary to maintain their body weight and body condition. Results indicate that current feed recommendations underestimate cows' energy requirements for zero energy balance. Even though this study did not allow for separation of maintenance and pregnancy requirements, the results are important for on-farm decisions regarding feed budgeting in the dry period.

http://dx.doi.org/10.3168/jds.2012-6280. 